\title{
DO SENTIMENTO DE INJUSTIÇA À LUTA SOCIAL: MOVIMENTO NEGRO, ESTRATÉGIAS DE COMUNICAÇÃO E LUTA POR RECONHECIMENTO NO BRASIL
}

\author{
FROM FEELINGS OF INJUSTICE TO SOCIAL STRUGGLE: BLACK \\ MOVEMENT, COMMUNICATION STRATEGIES AND STRUGGLE FOR \\ RECOGNITION IN BRAZIL
DE SENTIMIENTOS DE INJUSTICIA A LA LUCHA SOCIAL: MOVIMIENTO NEGRO, ESTRATEGIAS DE COMUNICACIÓN Y LUCHA PER RECONOCIMIENTO EM BRASIL

Alicianne Gonçalves de Oliveira Doutoranda em Comunicação Social na Universidade Federal de Minas

Gerais alicianneg@gmail.com

\begin{abstract}
Resumo
O movimento negro brasileiro vem utilizando, ao longo de sua história, diferentes estratégias - comunicacionais, associativas e institucionais - para que a questão negra chegue à esfera pública do País. O presente artigo analisa essa trajetória do movimento negro a partir da década de 1970 e, para isso, utiliza a Teoria do Reconhecimento, de Axel Honneth. O trabalho compreende, assim, como as estratégias de comunicação, em conjunto com as associativas e institucionais, conseguiram: (1) influenciar a articulação entre sentimentos de injustiça no plano individual e em uma dimensão social, e, assim; (2) propiciar um cenário favorável para que os negros articulassem um quadro intersubjetivo para interpretar a sua realidade, gerando motivação para a luta por justiça social.
\end{abstract}

Palavras-chave:Movimento negro. Reconhecimento. Esferapública.

\begin{abstract}
During its history, the Brazilian black movement has used different strategies communicative, associative and institutional - to raise the issue of racial inequality in the Brazilian public sphere. This paper analyzes the actions of the black movement since the 1970s, using Axel Honneth's Theory of Recognition. The study highlights how communication strategies, together with associative and institutional ones, managed to: (1) influence the relationship between sense of harm at the individual level, and feelings of injustice at a social level, and (2) provide favorable conditions for the black people to articulate an intersubjective framework to interpret their reality, motivating them to struggle for social justice.
\end{abstract}

Key words:Black movement. Recognition. Public sphere. 


\section{Resumen}

El movimiento negro brasileño viene utilizando, a lo largo de su historia, diferentes estrategias - comunicacionales, asociativas e institucionales - para que la cuestión negra llegue a la esfera pública del país. El presente artículo analiza esa trayectoria del movimiento a partir de la década de 1970 y, para eso, utiliza la Teoría del Reconocimiento, de Axel Honneth. La investigación comprende, así, cómo las estrategias de comunicación, en conjunto con las asociativas e institucionales, consiguieron: (1) influenciar la articulación entre sentimientos de daño a nivel individual y en una dimensión social; y (2) propiciar un escenario favorable para que los negros articulasen un cuadro intersubjetivo para interpretar su realidad, generando motivación para la lucha por justicia social.

Palabras clave: Movimiento negro. Reconocimiento. Esfera pública.

Esta obra está licenciada sob uma Licença CreativeCommons

\section{INTRODUÇÃO}

No caso das questões ligadas à população negra do Brasil, Átila Roque (2009, p. 261) defende que, até pouco tempo, “a esfera pública ${ }^{1}$ construída pela nossa limitada democracia não tinha espaço para o tema racial”. Segundo o autor, esse silêncio teria deixado negros e negras em uma espécie de "solidão civil", colocando para essa parcela da população os piores índices no tocante à educação, saúde, emprego e renda, e segurança pública (IPEA, 2008; HERINGER, 2008).

Mas esse cenário de quase silêncio em torno da temática foi modificado, principalmente, a partir dos anos de 1970. Entender esse percurso significa conhecer a história da ação de um importante ator da sociedade civil brasileira: o movimento negro. Conforme Maia (2001), é a ação discursiva dos atores que determina, em grande parte, se algo é de interesse comum ou não. Assim aconteceu com o referido movimento, um dos responsáveis por incluir o tema racial em nossa esfera pública.

Este artigo analisa, de forma breve, a ação do movimento negro. O objetivo aqui é lançar um olhar histórico sobre o tema, focando-se em exemplos das estratégias de comunicação, estratégias associativas e institucionais utilizadas pelo movimento a partir da década de 1970.

\footnotetext{
${ }^{1} \mathrm{O}$ artigo trabalha com a concepção de esfera pública como âmbito daquilo que é visível e discutível publicamente, como "uma rede adequada para a comunicação de conteúdos, tomadas de posição e opiniões", onde os fluxos comunicacionais se condensam em opiniões públicas (HABERMAS, 2003, p. 93).
} 
As estratégias analisadas neste artigo são compreendidas sob dois aspectos paralelos e convergentes. O primeiro considera que a atuação do movimento negro em nossa esfera pública representa, geralmente, o aprofundamento das ações junto à sociedade e ao Estado (SANTOS, 2009). Isso porque o trabalho do movimento corroborou e corrobora para que a questão negra esteja no debate público, mas que também seja tematizada, dramatizada a ponto de o Estado ter que assumi-la e elaborá-la (HABERMAS, 2003, p. 92). Na análise deste artigo, foca-se brevemente em como isso se deu no âmbito do Executivo Federal.

O segundo aspecto é que se observa que o processo apontado acima diz da imbricada relação entre trajetória do movimento e trajetória de elaboração de uma luta por reconhecimento por parte dos negros no Brasil. A noção de reconhecimento é um conceito chave nos estudos da terceira geração da Escola de Frankfurt e tem um quadro teórico convergente com o pensamento habermasiano, na medida, principalmente, em que destaca a intersubjetividade. O destaque é que, no quadro teórico de Axel Honneth, com que o artigo trabalha, "a intersubjetividade é conectada à noção de autorrealização, tida como referência para se compreender e se aferir as dimensões normativas de conflitos ético-políticos" (MAIA et al, 2014, p. 209).

E é por isso que a discussão honnethiana permite, na perspectiva deste trabalho, compreender as mudanças de estratégia do movimento que levaram a questão racial à esfera pública brasileira, compreendendo a forma como esse movimento trabalhou as experiências de desrespeito como impulso para a luta social.

\section{LUTA POR RECONHECIMENTO E ESTRATÉGIAS DO MOVIMENTO PÓS 70}

\subsection{Luta por reconhecimento e movimento negro brasileiro a partir de 1970: caminhos basilares para discussão}

Ao escolher falar sobre movimento negro a partir da Teoria do Reconhecimento, é importante esclarecer quem é esse grupo e quem ele pretende representar. Neste artigo, compartilha-se a concepção de Amilcar Araújo Pereira (2007, p. 235), que caracteriza o movimento negro como "o conjunto de entidades, organizações e indivíduos que lutam contra o racismo e por melhores condições de vida para a população negra, seja através de práticas culturais, de estratégias políticas, de iniciativas educacionais [...]”. Diversidade essa que é constituída por várias experiências de associativismo, por diferentes processos de 
sociabilização, disputas por posição e por ideias, definição de objetivos e ações ${ }^{2}$ (GOMES, 2007, p. 10).

Esse também é um movimento mais que secular. Desde o início da República brasileira, no final do século XIX, os negros, na maioria recém-libertos e marginalizados, começaram a se organizar em um movimento político de mobilização racial ${ }^{3}$ para lidar com as consequências de preconceitos e discriminações ainda vigentes. Com fases diversas e diferentes estratégias, o movimento negro no Brasil chegou à década de 1970 caracterizado por uma reconstrução étnica e cultural, pautado na valorização do ser negro, da cultura negra, além da luta pela melhoria da realidade social e econômica dessa parcela da população.

O percurso descrito acima pode ser entendido, a partir dos termos honnethianos, como um percurso por reconhecimento na sociedade brasileira. Axel Honneth, expoente da terceira geração da Escola de Frankfurt deu novo ímpeto à Teoria Crítica na medida em que defende a promoção e a identificação dos impulsos emancipatórios que existem na realidade social (MAIA et al, 2014, p. 199). Para isso, Honneth entende o conflito como estruturante da vida social, onde a luta se constrói baseada no reconhecimento que é recusado seja no plano das relações primárias, jurídicas ou sociais. No caso do movimento negro brasileiro, a luta por reconhecimento na sociedade brasileira foi trilhada nesses três planos e ligando autorrealização à justiça social.

O quadro proposto por Axel Honneth - inspirado em uma sorte de fontes, onde se destacam Hegel, Mead e a tradição da Antropologia Filosófica - trabalha com a ideia de que o reconhecimento é a forma mais importante de engajamento intersubjetivo e, assim, propõe um novo paradigma na Teoria Crítica (DERANTY, 2009). Como explica Maia e colaboradores (2014, p. 210), Honneth reconstrói a teoria da intersubjetividade e da socialização na medida em que para ele "o reconhecimento baseado na noção de autorrealização deve ser visto como um processo intersubjetivo, construído na e através da relação com os outros, e, portanto, dependente da interação". Essa perspectiva teórica, intrinsicamente social, coloca no centro de debates os conflitos existentes entre grupos, as formas de dominação social e as lutas de indivíduos e grupos para mudar ou ampliar as formas de reconhecimento na sociedade. A partir dessa perspectiva, Honneth (2003a) descreve três padrões intersubjetivos de

\footnotetext{
${ }^{2}$ Como aponta Domingues (2007), essa luta não se restringe somente aos negros. Como em outros movimentos, compartilham a luta e o desejo de mudança outros sujeitos não diretamente atingidos pelos problemas ou não diretamente beneficiados pelas políticas demandadas.

${ }^{3}$ Opta-se trabalhar com a perspectiva de Domingues (2007, p. 4), que caracteriza o movimento negro como "movimento político de mobilização racial (negra)". Como ele defende, considerar como movimento negro todos os movimentos que organizem em qualquer tempo e aspecto a partir de qualquer rubrica descendente de africanos no Brasil representaria, no mínimo, um problema do ponto de vista historiográfico.
} 
reconhecimento, dos quais dependeria a autorrealização do indivíduo; suas respectivas formas de relação do indivíduo com o self; suas respectivas formas de desrespeito ou "dano". Um padrão está ligado às relações primárias, onde o reconhecimento estaria associado ao amor e à amizade e garantiria como autorrelação prática a autoconfiança. Nas relações jurídicas, a forma de reconhecimento seria o direito, ligado ao autorrespeito do indivíduo. A última forma de reconhecimento, que aconteceria na comunidade de valores, seria a solidariedade. Essa forma se ligaria à autoestima do indivíduo, aqui reconhecido pelos demais a partir de suas características e capacidades.

Na teoria de Honneth, os três tipos de desrespeito ou "dano" - maus-tratos e violações; privação de direitos e exclusão; e degradação e ofensa - influenciam o surgimento tanto dos conflitos sociais quanto da resistência social. É importante ressaltar que, como aponta Deranty (2009, p. 310-311), a teoria honnethiana só se configura uma teoria social crítica quando Honneth liga, explicitamente, seus argumentos psicológico-sociais e teórico-sociais com a teoria dos movimentos sociais. Para a teoria do reconhecimento de Honneth, a fonte moral dos movimentos sociais são os "sentimentos de injustiça". Em outras palavras, o movimento social se constrói a partir de quando os sujeitos sob experiências de injustiça compreendem que suas experiências subjetivas são representativas também da experiência de um grupo (DERANTY, 2009, p. 311, 316). E em uma perspectiva prática, os movimentos sociais utilizam os recursos simbólicos que estão à sua disposição para conseguir mostrar que a injustiça é compartilhada por muitos e, assim, estabelecer as condições culturais para a resistência e a revolta (SILVA, 2000, p. 127). Ações que têm consequências no plano social e individual, como aponta Honneth:

[...] a resistência coletiva procedente da interpretação socialmente crítica dos sentimentos de desrespeito partilhados em comum, não é apenas um meio prático de reclamar para o futuro padrões ampliados de reconhecimento. [...] o engajamento nas ações políticas possui para os envolvidos também a função direta de arrancá-los da situação paralisante do rebaixamento passivamente tolerado e de lhes proporcionar, por conseguinte, uma autorrelação nova e positiva. (HONNETH, 2003a, p. 259).

No tocante às pesquisas na área da Comunicação, a Teoria do Reconhecimento vem ampliando "as perspectivas de investigação de fenômenos comunicativos que contribuem para a constituição intersubjetiva dos sujeitos", na medida em que lança uma nova abordagem para entender: as lutas em torno de representações e discursos midiáticos; a construção de uma 
semântica coletiva na esfera dos movimentos e grupos sociais; e o papel da autoexpressão dos sujeitos para as discussões ou para o ativismo (MAIA et al, 2014, p. 201).

Nessa perspectiva, as estratégias utilizadas pelo movimento negro brasileiro a partir da década de 1970 - associativas, comunicacionais e institucionais - conjugam as três formas de reconhecimento propostas por Honneth, seus respectivos tipos de relação do indivíduo com o self e de desrespeito. Através dessas estratégias, o movimento trilhou uma caminho de luta que atendeu a necessidade de autorrealização - em termos de autonomia e liberdade individual mas também em termos de inclusão social.

\subsection{Estratégias associativas e mudanças do plano íntimo ao social}

As experiências associativas são, desde a fase moderna do movimento, no final do século XIX, principalmente responsáveis por mudanças no plano íntimo e social na vida dos negros brasileiros. Em 1964, por exemplo, o golpe militar tinha desarticulado as forças do movimento negro e seus militantes passaram a ser "estigmatizados e acusados pelos militares de criar um problema que supostamente não existia, o racismo no Brasil” (DOMINGUES, 2007, p. 111). No entanto, mesmo nesse período de repressão política, pequenos grupos se reuniam em várias cidades para discutir a cultura negra e o contexto político.

A informalidade era, nessa época, uma forte característica do movimento negro, em sua grande parte, cultural (CUNHA JR, 2003). Essas experiências informais, embora não pudessem se organizar em uma luta política mais aberta ou não se configurassem como uma estratégia associativa enquanto formação de entidades, funcionavam como espaços onde se formavam novas identidades e solidariedades comunicativas capazes de tematizar novas questões e agregar novos atores (AVRITZER, 2000, p. 68). Assim, essas experiências funcionavam mais como um espaço onde as pessoas e os grupos trabalhavam as experiências de desrespeito, de ausência de reconhecimento nos planos primário, legal e social.

Com o advento da década de 1970, período de ascensão dos movimentos populares, sindical e estudantil, o movimento negro recomeçou a se organizar politicamente. Algumas experiências associativas ganharam destaque ao atingirem um maior número de pessoas em uma dimensão mais ampla do que as experiências anteriores e realizarem, assim, um movimento negro popular. O Ilê Aiyê, criado em 1974, em Salvador, é exemplo de experiências que objetivavam conscientizar as pessoas negras e fortalecer uma ação política e cultural voltada para a temática afro-brasileira (CUNHA, 2000). A partir de iniciativas como essa, o movimento buscou fortalecer a consciência dos sujeitos enquanto negros e lutar contra 
maus-tratos e violações, influenciando uma relação de autoconfiança. Além disso, boa parte das experiências associativas desse período processaram a experiência do reconhecimento negado na sociedade brasileira para provocar mudanças também na comunidade de valores.

Honneth (2003a, p. 207) explica que nas sociedades contemporâneas, “[...] as relações de estima social estão sujeitas a uma luta permanente na qual os diversos grupos procuram elevar, com os meios da força simbólica e em referência às finalidades gerais, o valor das capacidades associadas à sua forma de vida”. Por isso, as pessoas buscam a valorização daquilo que as caracteriza e as diferencia. E isso acontece na comunidade de valores, já que é lá onde estão que os quadros partilhados de significação. Quadros esses que podem ser revistos e, por isso mesmo, vários conflitos buscam, exatamente, a sua reconfiguração (MENDONÇA, 2007, p. 173). A forma, então, como o movimento negro brasileiro escolheu se opor à opressão e buscar a reconfiguração dos quadros de significação foi reivindicar a dignidade e o orgulho raciais. Essa ação de valorização do negro brasileiro deu frutos visíveis. Surgiram os blocos afros, os grupos de rap e os bailes funk. Além disso, aumentou o número de brasileiros que antes se identificavam como morenas ou brancas, mas que agora se identificam como negras.

Já próximo à década de 1980, quando a sociedade civil brasileira se articulava em um ambiente nacional favorável, o movimento negro intensificou estratégias no tocante à mudança de valores, que, como Honneth afirma (2003a, p. 200), são culturalmente definidos. No Programa de Ação do Movimento Negro Unificado (MNU), organização criada em 1979, havia, por exemplo, a defesa da transformação do movimento negro em movimento de massa. Para isso, era defendida a classificação bipolar da população, entre brancos e negros, esses abrangendo todos os pretos e pardos. Outra estratégia política vinda de coletivos e entidades foi o reforço da promoção de uma identidade étnica própria do negro, a partir do discurso da negritude e do resgate das suas raízes ancestrais. No Programa de Ação do MNU já havia a luta pela introdução da História da África e do negro no Brasil nos currículos escolares. Ideia que viraria lei somente em 2003.

Os grupos desse período também defendiam fortemente a desmistificação da democracia racial brasileira. Com a ideia de um povo formado pela mistura harmoniosa - e, por isso, sem preconceito, um povo mestiço simplesmente, um povo brasileiro - o Estado brasileiro, do Estado Novo à ditadura militar, pretendeu transformar a imagem do negro enquanto povo e banir do pensamento social brasileiro o conceito de raça, e consequentes padrões de diferenciação, substituindo-o pelos conceitos de cultura e de classe social (GUIMARÃES, 2002, p.110). Isso teria influenciado como a temática negra é trabalhada na 
esfera pública brasileira. A dificuldade que a sociedade brasileira tem de reconhecer e discutir o racismo, por exemplo, não pode ser encarada como um tabu social simplesmente, mas como exemplo de controle ideológico da esfera pública, como afirma Martins (2005, p. 185).

O mito da democracia racial pode ser compreendido a partir do que Honneth (2006) denomina como formas de reconhecimento ideológico. Para ele, esse tipo de reconhecimento, oposto da forma justificada, apresenta-se como (1) favorável, positiva ao grupo, (2) digna de crédito, com componentes realistas, e (3) contrastante, trazendo uma noção valorativa. No entanto, o reconhecimento ideológico teria caráter ficcional porque seria promessa de reconhecimento que não se efetiva, na medida em que não consegue dar condições para a mudança valorativa se materializar. Isso porque as condições institucionais necessárias não seriam compatíveis com a ordem social dominante (2006, p. 147).

A lógica do mito da democracia racial enquanto forma ideológica de reconhecimento opera no marco das razões historicamente existentes (HONNETH, 2006, p. 142), dos valores historicamente construídos. Em outras fases do movimento negro, a ideia de democracia racial era bem-vinda e não questionada. $O$ conflito entre essa visão oficial e a realidade de preconceito e discriminações vivida pelos negros brasileiros não era elaborado pelos grupos, não era exposto nas experiências associativas nem questionado na interlocução que se conseguia ter com o Estado ${ }^{4}$. Por se mostrar positiva, crível e contrastante, a ideia de democracia racial, acabava, na verdade, baseando padrões que oprimiam os negros. Mas essa opressão não ficava evidente, não era entendida como opressão, o que acabava legitimando as hierarquias.

O que o movimento negro fez, ao propor a desmistificação, foi mostrar o núcleo irracional das ideologias do reconhecimento. Núcleo esse que não está na superfície semântica das palavras, mas na discrepância entre promessa valorativa e realização material (HONNETH, 2006, p. 133). O movimento faz isso ao mostrar que a sociedade da democracia racial, supostamente sem barreiras, onde todos estão incluídos, é na verdade uma sociedade que impõe obstáculos à população negra, deixando esse grupo na base da pirâmide de hierarquias e subordinação sociais. Uma sociedade onde os negros, que historicamente sofrem com a exclusão, têm apenas uma promessa de reconhecimento.

\footnotetext{
${ }^{4}$ Mas houve casos, não muitos, em que a desmistificação da democracia racial foi defendida pelo movimento em fases anteriores. Um exemplo foi o trabalho de organizações como o Teatro Experimental do Negro (TEN), fundado em 1944 no Rio de Janeiro e cuja principal liderança foi Abdias do Nascimento.
} 
Por pensar que esse reconhecimento ainda precisa ser alcançado ou, pelo menos, alcançado em uma escala maior, as estratégias de ação na comunidade de valores ainda persistem na luta por reconhecimento dessa parcela da população.

\subsection{Estratégias institucionais e ações nos planos legal e das políticas públicas}

A teoria social de Honneth não pensa as instituições como "meramente 'disciplinadoras", mas como atores que, em uma democracia constitucional, "salvaguardam a autonomia individual e permitem a afirmação das diferenças concernentes à autorrealização dos indivíduos e às formas de vida culturalmente variadas" (MAIA et al, 2014, p. 201). Nesse sentido, a transformação do movimento negro em movimento de massa e a formação de uma rede de alianças para a luta contra o racismo a partir da década de 1970 não pode ser pensada sem a relação entre movimento e esfera de decisão política formal. Afinal, os negros formam um daqueles grupos que, como ressalta Maia (2012), demandam, na sociedade contemporânea, reconhecimento social e legal e participam não somente da esfera pública, mas também das decisões nos arranjos institucionais.

Antes do período de redemocratização, o movimento negro no Brasil já havia tentado interlocuções com o Estado ${ }^{5}$. No entanto, essa relação só se traduziu em políticas públicas e ações legais que beneficiassem a população negra com a chegada da nova agenda de luta e com ambientes nacional e internacional favoráveis. Isso aconteceu com ressalvas e críticas dentro do próprio movimento. Alguns grupos se colocavam contrários à ideia de interlocução com o Estado, que, por sua vez, durante muito tempo, mostrou-se "refratário e hostil" a qualquer ação que, por exemplo, desmistificasse a ideologia da democracia racial brasileira (JACCOUD; BEGHIN, 2002, p. 15). Mas a partir do cenário de configuração do estado liberal democrático no Brasil, parte das organizações do movimento negro passou suas ações da denúncia para o uso de mecanismos jurídicos e políticos (SILVÉRIO, 2009) apesar das resistências internas do movimento.

Os primeiros resultados dessa mudança na ação do movimento aconteceram na década de 1980, quando das primeiras articulações entre movimento negro e organizações políticas como a Central Única dos Trabalhadores (CUT), o Partido Democrático Trabalhista (PDT) e o Partido dos Trabalhadores (PT). Especificamente no Poder Executivo, as primeiras experiências foram no âmbito municipal. Em 1984, o governo paulista de Franco Montoro

\footnotetext{
${ }^{5}$ Sobre isso ver Guimarães $(2001,2002)$.
} 
criou o Conselho de Participação e Desenvolvimento da Comunidade Negra. Em seguida, órgãos semelhantes surgiram em outros estados e municípios, ligados, principalmente, à área cultural. No âmbito do Executivo Federal, políticas e órgãos voltados à temática começaram a ser criados na gestão de José Sarney (1985-1990) e foram ampliados e diversificados nos mandatos de Fernando Henrique Cardoso (1995-1998 e 1999-2002) e Luiz Inácio Lula da Silva (2003-2006 e 2007-2010). Essa trajetória foi marcada pela pressão e pela participação de setores do movimento negro. Os órgãos criados nesse processo chamado de “institucionalização dos movimentos negros" (SANTOS, 2009) podem ser entendidos como uma tentativa, ainda em curso, de se institucionalizar padrões de reconhecimento. São exemplos a Fundação Cultural Palmares (FCP) e a Secretaria de Políticas de Promoção da Igualdade Racial (SEPPIR) e os Programas Nacionais de Direitos Humanos.

Essas novas reivindicações do movimento, as políticas públicas criadas pelo Estado e as leis aprovadas ${ }^{6}$ acompanham, assim, as mudanças da agenda do movimento. Uma agenda que abrange política de reconhecimento das diferenças e política de identidade, além de aliar política de cidadania, com a afirmação dos direitos civis dos negros, e política redistributiva, com a defesa de ações afirmativas ou compensatórias (GUIMARÃES, 2001). Características que fizeram a luta do movimento chegar ao âmbito legal e das políticas públicas com a dimensão ampla que caracteriza o reconhecimento na perspectiva honnethiana. Honneth defende que o reconhecimento não está reduzido à cultura ${ }^{7}$. Para ele, as condições para a autorrealização individual somente estão asseguradas quando os sujeitos experimentam reconhecimento intersubjetivo não apenas de sua autonomia pessoal, mas também de suas necessidades específicas e de suas capacidades particulares (HONNETH, 2003b, p. 189).

A luta por direitos e redistribuição de recursos empreendida pelo movimento negro brasileiro reforçam a noção de que e os confrontos econômicos fazem parte da luta por reconhecimento (HONNETH, 2003a, p. 208). Honneth esclarece que, uma vez que as relações de estima social estão ligadas a padrões de distribuição de renda, as injustiças de distribuição podem ser melhor entendidas "como uma expressão institucional do desrespeito social" (2003b, p. 114). E, por isso, as injustiças podem também ser compreendidas no âmbito das relações jurídicas. Conforme Honneth (2003a, p. 193), “[...] um sujeito respeitado encontra

\footnotetext{
${ }^{6}$ Destaco duas leis em especial: a Lei $\mathrm{n}^{\mathrm{o}}$ 12.711/2012, que institui cotas nas instituições federais de ensino, e o Estatuto da Igualdade Racial, Lei no $12.288 / 2010$.

${ }^{7}$ Não é objetivo deste artigo abordar as críticas feitas por Nancy Fraser $(2003,2006)$ à concepção de reconhecimento de Honneth. Para a autora, que parte da ideia de status de Max Weber, as lutas por reconhecimento acontecem em um mundo onde privação econômica e desrespeito cultural se entrelaçam e que a justiça, atualmente, exige os dois: reconhecimento e redistribuição. Fraser argumenta que o reconhecimento de Honneth não traz a contento essa dupla faceta. Honneth (2003b) argumenta que sua concepção de reconhecimento abrange sim os dois aspectos.
} 
reconhecimento jurídico não só na capacidade abstrata de poder orientar-se por normas morais, mas também na propriedade concreta de merecer o nível de vida necessária para isso.".

\subsection{Estratégias comunicacionais: caminhos para organização política e defesa de direitos}

O percurso apresentado acima não foi trilhado isoladamente. Se o movimento negro usa diferentes estratégias em sua luta por reconhecimento, ele faz isso de forma a integrar os recursos que lhe estão disponíveis. O papel da comunicação foi aí central, inclusive no sucesso das estratégias associativas e institucionais anteriormente citadas. Embora se compartilhe aqui com a ideia de que comunicação diz das várias formas de interação através das mais variadas linguagens, este artigo prioriza os processos que envolvem os media, que foram, historicamente, importantes para a luta do movimento negro por reconhecimento na sociedade brasileira. Afinal, como afirma Maia (2014, p. 243), os processos de mediação tecnológica são indispensáveis quando se aborda a construção de identidades e a expansão das relações de reconhecimento ou não-reconhecimento nas sociedades contemporâneas, complexas e multiculturais.

Nessa perspectiva, entende-se que a Teoria do Reconhecimento, ao lançar novas perspectivas de investigação dos fenômenos comunicacionais (MAIA et al, 2014, p. 201), reforça a ideia de que a esfera midiática é uma das várias esferas sociais que influenciam a trajetória de constituição da negritude no Brasil (COGO, MACHADO, 2010) e da luta desse grupo por justiça social. Um exemplo dessa importância é a imprensa negra, apontada como marco inicial do movimento (ALBERTI; PEREIRA, 2007a). Embrião das primeiras organizações no final do século XIX, jornais editados por negros eram espaço para denúncia e para temas que não tinham espaço na imprensa tradicional, comercial e branca. Os objetivos dessas primeiras experiências comunicacionais são prova de que as representações produzidas pelos media contribuem para a produção de significados culturais compartilhados, com influência na forma como os sujeitos se veem e veem o grupo ao qual pertencem e os demais coletivos (MAIA; ROCHA, 2014). E quando essas representações são problemáticas, elas podem ter consequências negativas, sustentando, inclusive, desigualdades sociais e políticas (FÜRSICH, 2010). Por isso mesmo, os meios de comunicação sempre foram um espaço de luta, um lugar para articulação, negociação e disputa pública em torno de um amplo leque de questões (MAIA, 2014, p. 27). 
Destacam-se aqui as ações do movimento junto aos meios de comunicação de dentro e de fora do movimento. Os movimentos sociais, quando objetivam ampliar sua influência, buscam atingir a agenda parlamentar e administrativa, a agenda dos partidos políticos, mas também a agenda dos media (MAIA, 2008a). Foi o que fez o movimento negro. A articulação entre movimento e Estado ocorreu à medida que o movimento passou a aproveitar os momentos de exposição pública, especialmente aqueles mediados pela imprensa (ALBERTI; PEREIRA, 2007b). Um exemplo emblemático de como o movimento soube unir as diferentes estratégias foi a Marcha Zumbi dos Palmares, em 1995, que, reunindo mais de 30 mil pessoas em Brasília, foi decisiva para que a questão negra fosse incluída nas políticas públicas federais.

Além disso, historicamente, o movimento vem utilizando diferentes tecnologias de comunicação e buscando gerar e distribuir conteúdo com representações mais plurais, construir e pautar o debate sobre a cidadania do grupo, e produzir espaços comunicacionais próprios, onde os negros tenham mais acesso e participação. O Jornal do $M N U$, criado em 1989, e os Cadernos Negros, publicados a partir de 1978, são exemplos emblemáticos de um processo de invenção de um discurso de representação e produção de identidades, através da proposição, inovadora para a época, de desestabilização de estereótipos, colocando os grupos minoritários nos centros de significação (SOUZA, 2006).

Ao longo das décadas, essas experiências foram diversificadas. Hoje, blogs, portais, jornais impressos, TVs online figuram no escopo de iniciativas (COGO; MACHADO, 2010). São dezenas de experiências comunicacionais de associações e grupos variados, dos políticos aos literários. Hoje, a comunicação do movimento é predominantemente online. Até a década dos anos 2000, havia várias experiências impressas, como o Jornal do MNU (1979-2003) e a fase impressa do Jornal İrohìn (1996-2006), mas que não continuaram, principalmente, devido ao alto custo do suporte impresso. O uso da internet pelo movimento começou, principalmente a partir de 2001, no processo de mobilização para III Conferência Mundial Contra o Racismo, a Discriminação Racial, a Xenofobia e a Intolerância Correlata, realizada em Durban, África do Sul. Nesse período, houve o fortalecimento da "cultura do online" dentro do movimento negro com o objetivo de proporcionar uma comunicação mais rápida entre os grupos dentro e fora do Brasil. Já havia alguns sites, mas o momento de preparação para Durban teria acelerado esse processo. Surgiram, assim, as listas de discussão, agências de notícias online, além de revistas, boletins e informativos online (SEBASTIÃO, 2007, p. 65$66)$. 
De uma forma geral, pode-se classificar esse conjunto de experiências como ferramenta e espaço de: (1) mobilização; (2) geração e distribuição de conteúdos visando à denúncia de discriminação e desigualdade raciais; (3) formação de uma memória coletiva de identidades e demandas; e (4) constituição pública de representações plurais da população negra. Isso se dá, claro, a partir da multiplicidade de concepções políticas, estratégias de luta e discursos do movimento (TRAPP, 2013; SOUZA, 2006), o que traz ressalvas em relação ao conjunto dessas experiências. Como lembra Della Porta (2012, p. 49-50), ao falar sobre o uso das novas tecnologias, há diferenças e tensões na forma como as várias organizações e ativistas fazem isso, o que reflete diferentes concepções de democracia e comunicação. $O$ movimento negro brasileiro não é unificado, as estratégias de comunicação também não são. Hoje, são blogs, sites, sites de redes sociais desenvolvidos por uma diversidade de atores, desde ativistas que sozinhos decidem desenvolver uma experiência de comunicação, coletivos de artistas, jovens ou comunicadores a entidades como organizações não-governamentais.

Apesar dessa diversidade característica, as estratégias de comunicação do movimento refletem uma forma de expor os conflitos e reivindicar reconhecimento a partir dos aspectos que são próprios desses ambientes digitais, que se configuram como espaço para a autoexpressão, para deliberação e conversação política, e para a ação coletiva e mobilização (MAIA, 2014). Especificamente nesse último caso, quando a voz dos atores da sociedade civil ganha os espaços midiáticos, ela pode mudar a forma como os temas são tradicionalmente tratados na sociedade (MAIA, 2008b). Além disso, quando os movimentos sociais utilizam os meios de comunicação, o Estado é levado a se posicionar publicamente, reforçando, assim as estratégias institucionais. Mas isso só acontece porque essas experiências, principalmente as gestadas dentro do próprio movimento, configuram-se, em um primeiro momento, para os negros como espaço de busca reconhecimento enquanto sujeito negro e enquanto grupo. Como acontece nas estratégias associativas, o sujeito se vê estimado dentro do grupo e, então, reivindica a estima entre os demais coletivos da sociedade. Assim, as iniciativas de comunicação do movimento se configuram como uma importante arena onde a luta por reconhecimento pode ser elaborada e o movimento negro brasileiro, construído.

\section{CONSIDERAÇÕES}

Ao longo da história da nossa República, o movimento negro utilizou diferentes estratégias junto ao Estado e à sociedade, que caracterizaram as ações desse grupo por reconhecimento no cenário brasileiro. A ampliação da agenda de reivindicações trazidas pelas 
novas entidades, as experiências com e nos meios de comunicação, a pressão e a participação em ações governamentais constituíram a luta do movimento a partir da década de 1970. Essa luta é baseada no reconhecimento negado à população negra nas relações primárias, jurídicas e na comunidade de valores, uma luta constituída contra a violação de condições sociais, econômicas e políticas acessíveis a todos, mas que não estão tão facilmente acessíveis a essa parcela da população.

Em conjunto, experiências associativas, institucionais e comunicacionais conseguiram influenciar (1) a articulação entre sentimentos de injustiça no plano individual e na dimensão social e, assim, (2) a forma como os negros, apesar dos conflitos e divergências do movimento, articularam um quadro intersubjetivo para interpretar a realidade comum, gerando motivação para a luta por justiça social. As estratégias de comunicação, especificamente, permitiram com que o movimento utilizasse as múltiplas formas de expressão, de que fala Maia e colaboradores (2014, p. 210-211), na busca por reconhecimento. Não só nas últimas décadas, mas em toda a história do movimento negro, vêse o uso dos meios de comunicação como forma de participação nas arenas discursivas, incluindo as instituições políticas formais, e como forma de promoção de ações coletivas, mobilização e protestos, com o objetivo de exercer coordenação e cooperação entre os cidadãos ou influenciar os processos de decisão.

É importante também pensar a luta desenvolvida pelo movimento negro dentro de um processo de evolução moral da sociedade (HONNETH, 2003a). A partir da década de 1970, ele conseguiu não somente introduzir a temática negra nas esferas de visibilidade e de discussão públicas, mas também discutir e reivindicar uma sociedade diferente, onde processos de individualização e inclusão social demostrassem um progresso nas relações de reconhecimento. Em outras palavras, uma sociedade onde todos pudessem experienciar mais aspectos de sua personalidade, ser totalmente incluídos no círculo de membros da sociedade e, dessa forma, ter a mesma chance de autorrealização (HONNETH, 2003b. 184-185).

Foi buscando esse objetivo que o movimento propôs uma forma diferente de os negros verem a si mesmos e de o país ver a si e a realidade dessa parcela da população. Mas esse é um processo ainda em curso. As conquistas, principalmente, no âmbito legal e da comunidade de valores, não significam para o movimento negro que as formas de reconhecimento existentes já são adequadas ou suficientes e que não precisam ser expandidas. 


\section{REFERÊNCIAS}

AVRITZER, Leonardo. Entre o diálogo e a reflexividade: a modernidade tardia e a mídia. In: AVRITZER, Leonardo; DOMINGUES, José Maurício. Teoria social e modernidade no Brasil. Belo Horizonte: UFMG, 2000. p. 61-84.

ALBERTI, Verena; PEREIRA, AmilcarAraujo (Org.). Histórias do movimento negro no Brasil: depoimentos ao CPDOC. Rio de Janeiro: Pallas; CPDOC - FGV, 2007a.

. ALBERTI, Verena; PEREIRA, Amilcar Araújo. Articulações entre movimento negro e Estado. In: GOMES, Angela de Castro (Org.). Direitos e cidadania: memória, política e cultura. Rio de Janeiro: FGV, 2007b. p. 93-103.

COGO, Denise; MACHADO, Sátira. Redes de negritude: usos das tecnologias e cidadania comunicativa de afro-brasileiros. In: XXXIII CONGRESSO BRASILEIRO DE CIÊNCIAS DA COMUNICAÇÃO - INTERCOM. Caxias do Sul, 2010.

CUNHA, Olívia Maria Gomes da. Depois da festa: movimentos negros e políticas de identidade no Brasil. In: ALVARES, Sonia E.; DAGNINO, Evelina; ESCOBAR, Arturo (Org.). Cultura e política nos movimentos sociais latino-americanos: novas leituras. Belo Horizonte: UFMG, 2000. p. 333-380.

CUNHA JUNIOR, Henrique. Movimento de consciência negra na década de 1970. Educação em Debate, ano 25, v. 2, n. 46, p. 47-54, 2003.

DELLA PORTA, Donatella. "Communication in movement: social movements as agents of participatory democracy.” In: LOADER, B. D. \& MERCEA, D. Social Media and democracy: Innovations in participatory democracy. London: Routledge, 2012. p.39-54.

DERANTY J. D. Beyond Communication: A Critical Study of Axel Honneth's Social Philosophy. Leiden: Brill, 2009.

DOMINGUES, Petrônio. Movimento negro brasileiro: alguns apontamentos históricos. Tempo, v. 12, n. 23, p. 100-122, 2007.

FRASER, Nancy. Social Justice in the Age of Identity Politics: redistribution, recognition and participation. In: FRASER, Nancy; HONNETH, Axel. Redistribution or Recognition?A political-Philosophical exchange.London/Nova York: Verso, 2003, p. 7-109

Da redistribuição ao reconhecimento? Dilemas da justiça numa era "pós-socialista". Cadernos de Campo, São Paulo, n. 14/15, p. 231-239, 2006.

FÜRSICH, Elfried. Media and the representation of Others. International Social Science Journal, vol.61, p.113-130, 2010.

GOMES, Angela de Castro. Prefácio. In: ALBERTI, Verena.; PEREIRA, Amilcar. Histórias do movimento negro no Brasil: depoimentos ao CPDOC. Rio de Janeiro: Pallas, 2007. p. 912 .

GUIMARÃES, Antonio Sérgio Alfredo. A questão racial na política brasileira (os últimos 
quinze anos). Tempo social, v. 13, n. 2, p. 121-142, 2001.

Classes, raças e democracia. São Paulo: Fundação de Apoio à Universidade de São Paulo, 2002.

HABERMAS, Jürgen. Direito e democracia: entre facticidade e validade, volume II. Rio de Janeiro: Tempo Brasileiro, 2003.

HERINGER, Rosana. Desigualdades raciais no Brasil: síntese de indicadores e desafios no campo das políticas públicas. Cad. Saúde Pública, v.18, suppl., p. 57-65, 2002.

HONNETH, Axel. Luta por reconhecimento: a gramática moral dos conflitos sociais. São Paulo: Editora 34, 2003a.

Redistribution as recognition: a response to Nancy Fraser. In: FRASER, Nancy; HONNETH, Axel. Redistribution or Recognition? A political-Philosophical exchange. London/Nova York: Verso, 2003b. p. 110-197.

El reconocimiento como ideología. Isegoría, n. 35, jul-dez, p. 129-150, 2006.

INSTITUTO DE PESQUISA ECONÔMICA APLICADA. Desigualdades raciais e políticas públicas: 120 anos após a abolição. Brasília, 2008. Comunicado da Presidência nº 4 .

JACCOUD, Luciana de Barros; BEGHIN, Nathalie. Desigualdades raciais no Brasil: balanço da intervenção governamental. Brasília: IPEA, 2002.

MAIA, Rousiley C. M. Democracia e a internet como esfera pública virtual: aproximando as condições do discurso e da deliberação. In: X ENCONTRO ANUAL DA COMPÓS, Brasília, 2001.

Conversação cotidiana e deliberação. In: GOMES, Wilson; MAIA, Rousiley C. M. Comunicação e democracia: problemas \& perspectiva. São Paulo: Paulus, 2008a. p. 195219.

Visibilidade midiática e deliberação pública. In: GOMES, Wilson; MAIA, Rousiley C. M. Comunicação e democracia: problemas \& perspectiva. São Paulo: Paulus, 2008b. p. 163-194.

Representação Política de Atores Cívicos: entre a imediaticidade da experiência e discursos de justificação. Revista Brasileira de Ciências Sociais, v. 27, n. 78, p. 97-112, 2012.

Recognition and the Media. London: Palgrave McMillan, 2014.

MAIA, Rousiley. C. M; ROCHA, Simone. M. The morality of recognition: adolescent slumdwellers discuss a TV series representation of their lives. In: Maia, Rousiley C. M.

Recognition and the Media. London: Palgrave McMillan, 2014.

MAIA, Rousiley. C. M., GARCEZ, Regiane. L., OLIVEIRA, Vanessa, MIOLA, Edna, NEVES, Bráulio. B., OLIVEIRA, Alicianne G., ROSSINI, Patrícia G. C., BARRETO, 
Diógenes L. S., CAL, Danila.A teoria crítica nos estudos da Comunicação: uma agenda empírica para o programa de JürgenHabermas e de Axel Honneth. In: Teorias da Comunicação no Brasil: reflexões contemporâneas. Salvador: EDUFBA, 2014, p. 197-219.

MARTINS, André Ricardo Nunes. Racismo e Imprensa: argumentação no discurso sobre as cotas para negros nas universidades. In: SANTOS, Sales Augusto dos Santos (Org.) Ações afirmativas e combate ao racismo nas Américas. Brasília: Ministério da Educação: UNESCO, 2005. p. 179-206.

MENDONÇA, Ricardo Fabrino. Reconhecimento em debate: os modelos de Honneth e Fraser em sua relação com o legado habermasiano. Revista de Sociologia Política, Curitiba, n. 29, p. 169-185, nov. 2007.

PEREIRA, AmilcarAraujo. O "Atlântico Negro" e a constituição do movimento negro contemporâneo no Brasil. ANPUH - XXIV SIMPÓSIO NACIONAL DE HISTÓRIA, São Leopoldo, 2007. p. 1-9.

ROQUE, Átila. Construção e desconstrução do silêncio: reflexões sobre o racismo e o antirracismo na sociedade brasileira. In: PAULA, Marilene de; HERINGER, Rosana (Org.). Caminhos convergentes: estado e sociedade na superação das desigualdades raciais no Brasil. Rio de Janeiro: Fundação Heinrich Boll, ActionAid, 2009. p. 259-274.

SANTOS, Marcio André de O. dos. Política negra e democracia no Brasil contemporâneo: reflexões sobre os movimentos negros. In: PAULA, Marilene de; HERINGER, Rosana (Org.). Caminhos convergentes: estado e sociedade na superação das desigualdades raciais no Brasil. Rio de Janeiro: Fundação Heinrich Böll, ActionAid, 2009. p. 227-258.

SEBASTIÃO, Ana Angélica. Memória, Imaginário e Poder: práticas comunicativas e de ressignificação das organizações de mulheres negras. Dissertação (mestrado). Programa de Pós-graduação em Comunicação e Cultura, Mídia e Mediações Sócio-Culturais. Escola de Comunicação da Universidade Federal do Rio de Janeiro. 190p. Rio de Janeiro, 2007.

SILVA, Josué Pereira da. Cidadania e reconhecimento. In: AVRITZER, Leonardo; DOMINGUES, José Maurício (Org.). Teoria social e modernidade no Brasil. Belo Horizonte: UFMG, 2000. p. 123-135.

SILVÉRIO, Valter Roberto. Evolução e contexto atual das políticas públicas no Brasil: educação, desigualdade e reconhecimento. In: PAULA, Marilene de; HERINGER, Rosana (Org.). Caminhos convergentes: estado e sociedade na superação das desigualdades raciais no Brasil. Rio de Janeiro: Fundação Heinrich Böll; ActionAid, 2009.

SOUZA, Florentina da Silva. Afro-descendência em Cadernos Negros e Jornal do MNU. Belo Horizonte: Autêntica, 2006.

TRAPP, Rafael Petry. Memória Discursiva e Antirracismo: Discursos Sobre "Movimento Negro" No Jornal Afro-Latino-América. Revista Memória em Rede, Pelotas, v.3, n.8, Jan./Jun.2013. p. 1-11. 
Original recebido em: 26/04/2015

Aceito para publicação em:05/08/2015

\section{Resumo sobre o autor}

Jornalista, mestre em Comunicação

(UFC), doutoranda em Comunicação

Social (UFMG); pesquisadora do Grupo de Pesquisa em Mídia e Esfera Pública (EME-UFMG); bolsista da Fundação Cearense de Apoio ao Desenvolvimento Científico e Tecnológico (Funcap). 